\title{
Alarms in the ICU: A study investigating how ICU nurses respond to clinical alarms for patient safety in a selected hospital in KwaZulu-Natal Province, South Africa
}

\author{
A Ramlaul, MSc; G Chironda, PhD; OrcID 0000-0003-1361-1495; P Brysiewicz, PhD; OrcID 0000-0001-6258-1603 \\ School of Nursing and Public Health, College of Health Sciences, University of KwaZulu-Natal, Durban, South Africa
}

Corresponding author: G Chironda (gerrychironda@yahoo.co.uk)

\begin{abstract}
Background. Advances in technology have facilitated the implementation of improved alarm management systems in the healthcare sector. There is a need to identify challenges encountered by intensive care unit (ICU) nurses with clinical alarm management systems in South Africa (SA) to ensure utilisation of these technological resources for patient safety.

Objective. To investigate how intensive care nurses respond to clinical alarms for patient safety in a selected hospital in KwaZulu-Natal Province, SA. Methods. A descriptive, non-experimental research design using the census sampling strategy was used to invite 120 nurses from four ICUs to complete an adapted, structured questionnaire. Descriptive statistics were used to analyse the data.

Results. We had 91 respondents who completed the questionnaires (response rate of $75.8 \%$ ). The majority of the respondents (85.7\%) strongly knew the purpose of clinical alarms and $45.1 \%$ strongly felt confident about adjusting and monitoring the clinical alarms. More than half of the nurses (53.8 \%) agreed to the existence of nuisance alarms that disrupted patient care (46.7\%) and contributed to lack of responses (52.7\%). While $76.9 \%$ strongly agreed with alarm sounds and displays to differentiate the priority of the alarms, $75.8 \%$ strongly agreed to the existence of proper documentation on setting alarms that are appropriate for each patient. The most frequent barriers were difficulty in setting alarms properly (51.6\%) and lack of training on alarm systems (47.8\%).

Conclusion. The complexity in setting the alarms, limited training and existence of false alarms was evident. Alarm-specific training is required to keep intensive care nurses updated with changes in technology to ensure patient safety.

Keywords. clinical alarms, patient safety, intensive care nurses, intensive care unit.
\end{abstract}

South Afr J Crit Care 2021:37(1):57-62. https://doi.org/10.7196/SAJCC.2021.v37i2.469

Contributions of the study. The findings of this present study highlighted the importance of understanding the alarm management system within the ICU environment of the healthcare sector in SA. Technological improvements, specialised trainings and clear clinical policies for alarm management are essential to improve patient safety.

Nurses working in an intensive care unit (ICU) are dependent on various medical devices to assist with patient monitoring, care and safety. ${ }^{[1]}$ There is an escalation in the number and type of innovative medical devices used in the ICU for patient care. ${ }^{[2]}$ The alarm systems of these medical devices (invasive and non-invasive) remain important components of the ICU environment as they alert nurses to the changing physiological parameters of the patient. ${ }^{[3,4]}$ Increased dependence on these devices is standard practice as they warn of abnormalities in vital signs and deteriorating patient condition that may not be visible. ${ }^{[5]}$

Visual access to physiological data, waveform configurations and false alarms are crucial determinants in timely responses of intensive care nurses to bedside alarm investigations. ${ }^{[6]}$ Hence, the effectiveness of alarm systems in an ICU is dependent on direct involvement of nurses in setting the monitors and responding to the alarming limits appropriately. ${ }^{[7]}$ Currently, the availability of the ideal one-to-one nurse patient ratio is not a realistic expectation due to the increasing prevalence of nurse attrition and an inexperienced workforce. ${ }^{[8]}$ Modern ICUs are equipped with clinical alarms that are technologically advanced in order to assist nurses ${ }^{[9]}$ however, nurses need to correctly interpret the clinical alarms. ${ }^{[10]}$ These alarms are expected to make the nurses' work easier but their associated hazards have been reported as being among the top ten health technological hazards encountered in the ICUs for several years. ${ }^{[4,11]}$

The increasing use of clinical alarm systems in the ICU setting leads to the concept of alarm fatigue. Alarm fatigue occurs when clinicians are exposed to a high occurrence of alarms, resulting in a failure to recognise and respond to true alarms that require bedside clinical intervention. ${ }^{[12]}$ Alarm fatigue is an important clinical problem and delayed responses may impair patient care, ${ }^{[13]}$ leading to patient deterioration and possible patient mortality in the ICU setting. ${ }^{[2]}$ Funk et al. ${ }^{[14]}$ highlighted the ability of nurses to respond to the alarming limits as they are aware that most of them are non-actionable or false. Unfortunately, most nurses are unsure of how they could prevent alarm fatigue. ${ }^{[15]}$ Studies carried out in Ireland ${ }^{[15]}$ and South Korea ${ }^{[16]}$ revealed the occurrence of false alarms as reported by $63.8 \%$ and $90 \%$ of nurses, respectively.

In the South African (SA) ICU setting, nurses are responsible for monitoring the patient's devices and alarms, hence there is a need for training and orientation to improve the nurse's knowledge. ${ }^{[1,14]}$ 
Understanding of the clinical alarms among ICU nurses is vital to guide the effective management and development of alarm system hospital policies that may further reduce false alarms and alarm fatigue. However, this area remains relatively unexplored and there is scarcity of literature on the response of nurses to clinical alarms in the ICU setting in SA.

\section{Methods Study design}

A descriptive, non-experimental research design was used, and data were collected using a self-administered questionnaire. The conceptual framework guiding this present study is the Shepherd's System Risk Model, ${ }^{[17]}$ which analyses device-related adverse events by considering components surrounding the situation and the persons that interact with these systems and devices. These components include device (human factors design), patient (passive causes), operator (education and training, diverted attention) and environment (internal).

\section{Study setting}

The present study was conducted in a private hospital in Durban, KwaZulu-Natal Province, SA. The hospital has three adult and one neonatal ICU. ICU 1 has 26 beds and manages cardiac patients such as those with myocardial infarction, post-catherisation, as well as cardiac patients undergoing procedures and needing advanced levels of care. ICU 2 has 25 beds and receives predominantly surgical cases that are elective or planned surgical cases that require advanced levels of care and also receives trauma cases. Patients in ICU 3 (9 beds) are mostly elective surgical cases for brain and cardiac surgery. Patients in ICU 4 ( 24 beds) are newborns and premature babies that require additional advanced levels of care.

\section{Population, sample and sampling}

The target population was all registered and enrolled nurses (either permanent or sessional staff) working in any of the four ICUs in the hospital. The South African Nursing Council regulations ${ }^{[18]}$ identifies a registered nurse (RN) as a practitioner who is qualified and competent to independently practise comprehensive nursing and midwifery, and is capable of assuming responsibility and accountability for such practice. An enrolled nurse (EN) carries out nursing care under the direct or indirect supervision or direction of a RN. Sessional refers to non-permanent staff working through nursing agencies. These registered and enrolled bedside nurses were directly involved in setting and managing alarm limits for their allocated patients. Using a census sampling strategy, all of the 120 RNs and ENs working in the ICU units were targeted.

The inclusion criteria were: (i) registered and enrolled nurses who worked at least 1 month in the ICU at the study hospital; (ii) ICU and non-ICU trained nurses; and (iii) sessional nurses meeting the criteria and working during the data collection period.

\section{Research tool}

A self-administered questionnaire was developed by the research team, incorporating the alarm fatigue questionnaire and the clinical alarms survey. ${ }^{[2,19]}$ Approval to use these two questionnaires was obtained from their developers. Items in these questionnaires deemed not applicable to the SA context, namely questions related to other country-specific organisations for patient safety and communication systems such as pagers, were excluded.
The questionnaire comprised of three sections. Section A requested demographic data and section B (21 items) contained alarm-related information aligned to the components of the Shepherd's System Risk Model. ${ }^{[17]}$ The respondents were asked to respond using a 5-point Likert scale: strongly agree, agree, neutral, disagree and strongly disagree. Section $\mathrm{C}$ consisted of nine items related to the challenges or barriers to the management of clinical alarms. The respondents were asked to rank the statements from 1 (most important) to 9 (least important).

\section{Validity and reliability}

We utilised two tools, the alarm fatigue questionnaire and the clinical alarms survey. ${ }^{[2,19]}$ Alignment of the objectives of the study to the questionnaire items was done, enhancing the content validity of the current tool. Pre-testing of the questionnaire was done with five RNS working in the ICUs of the research setting. No problems were highlighted, and no changes were made to the tool. Their data were not included in the present analysis. The established reliability of both of the questionnaires prior to them being combined was not highlighted by the researchers of the previous tools. However, the reliability coefficient analysis, which was the internal consistency of the newly combined structured tool for the study, was 0.71 . This indicated that the tool was an acceptable measure of the variables under study. ${ }^{[20]}$

\section{Data collection process}

Data were collected in October 2015 over a 2-week period. After obtaining ethical approval and permission from hospital management, AR made appointments with the unit managers of the respective ICUs in order to explain the objective of the present study and asked for access to the intensive care nurses. The distribution of the questionnaires was done on duty time as per agreement with hospital management. The respondents were given two envelopes; the first contained a detailed information sheet with details of the objective of the study and the consent form. A second envelope contained the questionnaire. The respondents were asked if they agreed to participate in the study and if so, to then sign the consent form. They were asked to complete the questionnaire at their convenience, and this was then returned to the unit manager in a sealed envelope. AR collected these sealed envelopes from the unit managers on a daily basis.

\section{Data analysis}

Data were cleaned, coded and entered into the SPSS software, version 23 (IBM Corp., USA) for analysis. Descriptive statistics in the form of frequencies and percentages were used to analyse the data. Crosstabulations were carried out between the nursing categories and training on clinical alarm monitoring system and functionality.

\section{Ethical considerations}

Ethical approval was obtained from the University of KwaZulu-Natal Ethics Committee (ref. no. HSS/0714/015M) and the hospital research committee. Confidentiality and anonymity of the respondents' responses were maintained, and they were informed that they could withdraw from the study at any time. An information sheet explaining the nature of the research and the rights of the respondents was provided to ensure informed consent was obtained prior to participating in the study. A signed consent form was completed and was collected separately from the completed questionnaires received to ensure that no participant could be linked to their completed questionnaire, thus ensuring their anonymity. 


\section{Results}

We distributed 120 questionnaires to nurses and received 91 responses, resulting in a response rate of $75.8 \%$.

\section{Demographic data}

Table 1 shows the demographic characteristics of the study respondents. Almost a third of the respondents (32\%) were from ICU 1, 24\% from ICU 4, and ICU 2 and 3 each accounted for $22 \%$ of the respondents. Most of the respondents were permanent non-ICU trained RNs (40.7\%). Overall, $60.4 \%$ of respondents had 7 years or more of nursing experience. The majority $(72.5 \%)$ had only received orientation regarding the alarm monitoring system and its functionality and $11 \%$ trained further. Among respondents who received orientation or orientation plus training, $75.8 \%$ indicated that they found this to be adequate.

Table 2 reveals information on clinical alarms against the nursing categories. More than a third of the respondents (38.5) were permanent RNs who were non-ICU trained and had orientation only on the alarm monitoring system. The number of respondents who received both orientation and training were predominantly low for all of the nursing categories except for unit managers. None of the sessional RNs or ENs had received orientation and training.

\section{Alarm-related information}

Table 3 shows alarm-related information which is highlighted according to the components of the Shepherd's System Risk Model. ${ }^{[17]}$ Regarding the component of operator (education

Table 1. Demographic characteristics of the respondents $(N=91)$

\begin{tabular}{|c|c|}
\hline Variable & $n(\%)$ \\
\hline \multicolumn{2}{|l|}{ Distribution of ICU nurses } \\
\hline ICU 1 & $29(31.8)$ \\
\hline ICU 2 & $20(22.0)$ \\
\hline ICU 3 & $20(22.0)$ \\
\hline ICU 4 & $22(24.2)$ \\
\hline \multicolumn{2}{|l|}{ Nursing category } \\
\hline Permanent RN ICU trained & $25(27.5)$ \\
\hline Permanent RN non-ICU trained & $37(40.6)$ \\
\hline Permanent EN & $12(13.2)$ \\
\hline Unit managers & $3(3.3)$ \\
\hline Sessional RN ICU trained & $2(2.2)$ \\
\hline Sessional RN non-ICU trained & $4(4.4)$ \\
\hline Sessional EN & $8(8.8)$ \\
\hline \multicolumn{2}{|l|}{ Years of experience of respondents } \\
\hline $0-3$ years & $21(23.0)$ \\
\hline $4-6$ & $15(16.5)$ \\
\hline $7-11$ & $25(27.5)$ \\
\hline$\geq 12$ & $30(33.0)$ \\
\hline \multicolumn{2}{|c|}{ Training received on alarm monitoring system and its functionality } \\
\hline No training and orientation received & $15(16.5)$ \\
\hline Orientation only & $66(72.5)$ \\
\hline Training received after orientation & $10(11.0)$ \\
\hline \multicolumn{2}{|c|}{ Adequacy of training and orientation received } \\
\hline Yes & $69(75.8)$ \\
\hline No & $22(24.2)$ \\
\hline
\end{tabular}

Table 2. Cross-tabulation of clinical alarms training and nursing categories $(N=91)$

\begin{tabular}{llll}
\hline Nursing category & $\begin{array}{l}\text { Orientation, } \\
\boldsymbol{n}(\%)\end{array}$ & $\begin{array}{l}\text { Orientation and } \\
\text { training, } \boldsymbol{n}(\%)\end{array}$ & $\begin{array}{l}\text { No training and } \\
\text { orientation, } \boldsymbol{n}(\%)\end{array}$ \\
\hline Permanent RN ICU trained & $21(23.1)$ & $4(4.4)$ & 0 \\
Permanent RN non-ICU trained & $35(38.5)$ & $1(1.1)$ & $1(1.1)$ \\
Permanent EN & $4(4.4)$ & $2(2.2)$ & $6(6.6)$ \\
Unit managers & 0 & $3(3.3)$ & 0 \\
Sessional RN ICU trained & 0 & 0 & $2(2.2)$ \\
Sessional RN non-ICU trained & 0 & 0 & $4(4.4)$ \\
Sessional EN & $6(6.6)$ & 0 & $2(2.2)$
\end{tabular}

$\mathrm{RN}=$ registered nurse; $\mathrm{EN}=$ enrolled nurse; $\mathrm{ICU}=$ intensive care unit

and training), the majority of the respondents $(85.7 \% ; n=78)$ strongly agreed that they knew the purpose of the clinical alarms, and $45.1 \%$ $(n=41)$ strongly agreed they felt confident in adjusting and monitoring the alarm parameters. In terms of the component device (human factors design), the majority of the respondents (76.9\%; $n=70$ ) strongly agreed that alarm sounds and/or visual displays should differentiate the priority of the alarms, $61.5 \%(n=56)$ strongly agreed that the alarm sounds and/or visual displays needed to be distinct based on the parameter or source of the alarm, and 59.3\% ( $n=54)$ strongly agreed that multiple senses needed to be impacted by the alarms. Concerning the parameter patient (passive causes), more than half of the respondents $(53.8 \% ; n=49)$ supported the existence of nuisance alarms which disrupted patient care $(46.7 \% ; n=42)$, contributed to lack of responses $(52.7 \% ; n=48)$ and reduced trust in alarms (35.6\%; $n=32)$.

For the parameter operator (diverted attention), 56\% ( $n=51)$ disagreed that they were overwhelmed by the number of alarms, $60.4 \%(n=55)$ disagreed that alarms could not be heard and were thus missed, and 59.3\% ( $n=54)$ disagreed with the statement that they got confused with the sources of the alarms. With respect to the environmental (internal) parameter, $51.6 \%(n=47)$ strongly agreed that the alarms were adequate, while $75.8 \%(n=69)$ agreed that they were sensitive and responsive to alarms. The majority of the respondents $(73.6 \%$; $n=67$ ) agreed to the existence of a requirement in their institutions to document the setting of appropriate alarms for each patient.

\section{Barriers to management of clinical alarms}

Table 4 identifies barriers to the management of clinical alarms. The highest ranked barriers were difficulty in setting alarms properly (51.6\%; $n=47)$, lack of training on the alarm systems (47.8\%; $n=43)$, and difficulty in hearing alarms, identifying the source of an alarm and understanding the priority of an alarm ranked at the same level $(46.2 \%$; $n=42)$.

\section{Discussion}

The operators of the clinical alarms on the equipment in the ICU environment were predominately the ICU nurses who were either registered ICU trained, or non-ICU trained and enrolled nurses. The present study revealed a greater number of nurses who worked in the ICU were non-ICU trained. Similar findings were reported by Meng'anyi et al., ${ }^{[3]}$ who found that a majority of nurses working in the ICU were non-ICU trained. 
Table 3. Alarm-related information $(N=91)$

\begin{tabular}{|c|c|c|c|c|c|c|}
\hline Questionnaire item & $\begin{array}{l}\text { Strongly agree, } \\
n(\%)\end{array}$ & $\begin{array}{l}\text { Agree, } \\
n(\%)\end{array}$ & $\begin{array}{l}\text { Neutral, } \\
n(\%)\end{array}$ & $\begin{array}{l}\text { Disagree, } \\
n(\%)\end{array}$ & $\begin{array}{l}\text { Strongly disagreed, } \\
n(\%)\end{array}$ & $\begin{array}{l}\text { Missing data, } \\
n(\%)\end{array}$ \\
\hline \multicolumn{7}{|l|}{ Operator (education and training) } \\
\hline $\begin{array}{l}\text { The purpose of clinical alarms is to alert staff } \\
\text { of an existing or potentially hazardous patient } \\
\text { condition }\end{array}$ & $78(85.7)$ & $10(11.0)$ & 0 & 0 & $2(2.2)$ & $1(1.1)$ \\
\hline $\begin{array}{l}\text { I feel confident in adjusting and monitoring } \\
\text { alarm parameters in order to reduce nuisance/ } \\
\text { false alarms }\end{array}$ & $41(45.1)$ & $33(36.3)$ & $4(4.4)$ & $7(7.7)$ & $3(3.3)$ & $3(3.3)$ \\
\hline $\begin{array}{l}\text { Properly setting alarm parameters and alerts is } \\
\text { overly complex on existing devices }\end{array}$ & $5(5.5)$ & $26(28.6)$ & $10(11.0)$ & $32(35.2)$ & $15(16.5)$ & $3(3.3)$ \\
\hline \multicolumn{7}{|l|}{ Device (human factors design) } \\
\hline $\begin{array}{l}\text { Alarm sounds and/or visual displays should } \\
\text { differentiate the priority of alarm }\end{array}$ & $69(75.8)$ & $17(18.7)$ & $3(3.3)$ & 0 & $1(1.1)$ & $1(1.1)$ \\
\hline $\begin{array}{l}\text { Alarm sounds and/or visual displays should be } \\
\text { distinct based on the parameter or source (e.g. } \\
\text { device) }\end{array}$ & $56(61.5)$ & $26(28.6)$ & $4(4.4)$ & $2(2.2)$ & $1(1.1)$ & $2(2.2)$ \\
\hline $\begin{array}{l}\text { Alarms should impact multiple senses (audible, } \\
\text { visual, proprioceptive, etc.) }\end{array}$ & $54(59.3)$ & $28(30.8)$ & $4(4.4)$ & 0 & $2(2.2)$ & $3(3.3)$ \\
\hline $\begin{array}{l}\text { The medical equipment used on my unit/floor } \\
\text { has distinct outputs (sounds, repetition rates, } \\
\text { visual displays, etc.) that allow differentiation of } \\
\text { the source of the alarm }\end{array}$ & $33(36.3)$ & $48(52.7)$ & $6(6.6)$ & $1(1.1)$ & $1(1.1)$ & $2(2.2)$ \\
\hline \multicolumn{7}{|l|}{ Patient (passive causes) } \\
\hline $\begin{array}{l}\text { Nuisance alarms contribute to lack of responses } \\
\text { by many nurses }\end{array}$ & $15(16.5)$ & $48(52.7)$ & $9(9.9)$ & $12(13.2)$ & $7(7.7)$ & 0 \\
\hline Nuisance alarms disrupt patient care & $12(13.2)$ & $42(46.2)$ & $15(16.5)$ & $10(11.0)$ & $11(12.1)$ & $1(1.1)$ \\
\hline Nuisance alarms occur frequently & $5(5.5)$ & $49(53.8)$ & $11(12.1)$ & $13(14.3)$ & $8(8.8)$ & $5(5.5)$ \\
\hline $\begin{array}{l}\text { Nuisance alarms reduce trust in alarms and } \\
\text { cause caregivers to turn alarms off at times other } \\
\text { than setup or procedural events }\end{array}$ & $18(19.8)$ & $32(35.2)$ & $15(16.5)$ & $16(17.6)$ & $9(9.9)$ & $1(1.1)$ \\
\hline \multicolumn{7}{|l|}{ Operator (diverted attention) } \\
\hline $\begin{array}{l}\text { I feel overwhelmed by the number of alarms on } \\
\text { the unit }\end{array}$ & $5(5.5)$ & $14(15.4)$ & $17(18.7)$ & $51(56.0)$ & $3(3.3)$ & $1(1.1)$ \\
\hline $\begin{array}{l}\text { Clinical alarms are a significant contributor to } \\
\text { my stress level }\end{array}$ & $3(3.3)$ & $8(8.8)$ & $20(22.0)$ & $37(40.7)$ & $20(22.0)$ & $3(3.3)$ \\
\hline $\begin{array}{l}\text { There have been frequent instances where alarms } \\
\text { could not be heard and were missed }\end{array}$ & $5(5.5)$ & $10(11)$ & $6(6.6)$ & $55(60.4)$ & $14(15.4)$ & $1(1.1)$ \\
\hline $\begin{array}{l}\text { When a number of devices with alarms are used } \\
\text { with a patient, it can be confusing to determine } \\
\text { which device is in alarm mode }\end{array}$ & $5(5.5)$ & $12(13.2)$ & $6(6.6)$ & $54(59.3)$ & $13(14.3)$ & $1(1.1)$ \\
\hline $\begin{array}{l}\text { Have you experienced alarm fatigue in the past } \\
6 \text { months? }\end{array}$ & $6(6.6)$ & $22(24.2)$ & $18(19.8)$ & $28(30.8)$ & $15(16.5)$ & $2(2.2)$ \\
\hline \multicolumn{7}{|l|}{ Environment (internal) } \\
\hline $\begin{array}{l}\text { The alarms used on my floor/area of the hospital } \\
\text { are adequate to alert staff of potential or actual } \\
\text { changes in a patient's condition }\end{array}$ & $47(51.6)$ & $39(42.9)$ & $1(1.1)$ & $1(1.1)$ & $1(1.1)$ & $2(2.2)$ \\
\hline $\begin{array}{l}\text { There is a requirement in your institution } \\
\text { to document that the alarms are set and are } \\
\text { appropriate for each patient }\end{array}$ & $69(75.8)$ & $11(12.1)$ & $3(3.3)$ & $5(5.5)$ & $3(3.3)$ & 0 \\
\hline $\begin{array}{l}\text { The staff is sensitive to alarms and respond } \\
\text { quickly }\end{array}$ & $36(39.6)$ & $33(36.3)$ & $9(9.9)$ & $10(11.0)$ & 0 & $3(3.3)$ \\
\hline $\begin{array}{l}\text { Policies and procedures exist within the facility } \\
\text { to regulate alarms and they are followed }\end{array}$ & $10(11.0)$ & $67(73.6)$ & $7(7.7)$ & $2(2.2)$ & $2(2.2)$ & $3(3.3)$ \\
\hline $\begin{array}{l}\text { Environmental background noise has interfered } \\
\text { with alarm recognition }\end{array}$ & $3(3.3)$ & $13(14.3)$ & $10(11.0)$ & $57(62.6)$ & $6(6.6)$ & $2(2.2)$ \\
\hline
\end{tabular}

Despite the years of experience of the majority of the nurses (7 years and over), the number of ICU nurses who received both education and orientation on alarm management was low. While the majority of the
ICU nurses had received orientation to the new surroundings of clinical alarms at the time, they were new employees in ICU, the minority (11\%) received training on knowledge and skills of managing the clinical 
Table 4. Barriers to effective management of clinical alarms $(N=91)$

\begin{tabular}{|c|c|c|c|c|c|c|c|c|c|c|}
\hline Questionnaire item & $\begin{array}{l}1 \\
\text { Most } \\
\text { important } \\
n(\%)\end{array}$ & $\begin{array}{l}2 \\
n(\%)\end{array}$ & $\begin{array}{l}3 \\
n(\%)\end{array}$ & $\begin{array}{l}4 \\
n(\%)\end{array}$ & $\begin{array}{l}5 \\
n(\%)\end{array}$ & $\begin{array}{l}6 \\
n(\%) \\
\end{array}$ & $\begin{array}{l}7 \\
n(\%)\end{array}$ & $\begin{array}{l}8 \\
n(\%)\end{array}$ & $\begin{array}{l}9 \\
\text { Least } \\
\text { important } \\
n(\%) \\
\end{array}$ & $\begin{array}{l}\text { No } \\
\text { response } \\
n(\%) \\
\end{array}$ \\
\hline \multicolumn{11}{|c|}{ Operator priority ranked statements } \\
\hline $\begin{array}{l}\text { Difficulty in setting } \\
\text { alarms properly }\end{array}$ & $47(51.6)$ & $6(6.6)$ & $8(8.8)$ & $3(3.3)$ & $10(11.0)$ & $3(3.3)$ & $2(2.2)$ & $2(2.2)$ & $10(11.0)$ & 0 \\
\hline $\begin{array}{l}\text { Lack of training on } \\
\text { alarm systems }\end{array}$ & $43(47.3)$ & $7(7.7)$ & $4(4.4)$ & $6(6.6)$ & $7(7.7)$ & $5(5.5)$ & $3(3.3)$ & $5(5.5)$ & $10(11.0)$ & $1(1.1)$ \\
\hline $\begin{array}{l}\text { Difficulty in hearing } \\
\text { alarms when they occur }\end{array}$ & $42(46.2)$ & $7(7.7)$ & $4(4.4)$ & $8(8.8)$ & $6(6.6)$ & $3(3.3)$ & $4(4.4)$ & $5(5.5)$ & $11(12.1)$ & $1(1.1)$ \\
\hline $\begin{array}{l}\text { Difficulty in identifying } \\
\text { the source of an alarm }\end{array}$ & $42(46.2)$ & $8(8.8)$ & $5(5.5)$ & $3(3.3)$ & $10(11.0)$ & $1(1.1)$ & $2(2.2)$ & $5(5.5)$ & $13(14.3)$ & $2(2.2)$ \\
\hline $\begin{array}{l}\text { Difficulty in } \\
\text { understanding the } \\
\text { priority of an alarm }\end{array}$ & $42(46.2)$ & $16(17.6)$ & $4(4.4)$ & $3(3.3)$ & $7(7.7)$ & $1(1.1)$ & 0 & $4(4.4)$ & $12(13.2)$ & $2(2.2)$ \\
\hline $\begin{array}{l}\text { Over-reliance on } \\
\text { alarms to call attention } \\
\text { to patient problems - } \\
\text { operator }\end{array}$ & $38(41.8)$ & $11(12.1)$ & $5(5.5)$ & $7(7.7)$ & $6(6.6)$ & $5(5.5)$ & $8(8.8)$ & $6(6.6)$ & $4(4.4)$ & $1(1.1)$ \\
\hline $\begin{array}{l}\text { Frequent false alarms, } \\
\text { which lead to reduced } \\
\text { attention or response } \\
\text { to alarms when } \\
\text { they occur }\end{array}$ & $33(36.3)$ & $10(11.0)$ & $6(6.6)$ & $9(9.9)$ & $9(9.9)$ & $5(5.5)$ & $2(2.2)$ & $6(6.6)$ & $10(11.0)$ & $1(1.1)$ \\
\hline $\begin{array}{l}\text { Inadequate staff to } \\
\text { respond to alarms as } \\
\text { they occur }\end{array}$ & $32(35.2)$ & $8(8.8)$ & $8(8.8)$ & $11(12.1)$ & $6(6.6)$ & $8(8.8)$ & $3(3.3)$ & $3(3.3)$ & $10(11.0)$ & $2(2.2)$ \\
\hline $\begin{array}{l}\text { Noise competition } \\
\text { from non-clinical } \\
\text { alarms and pages - } \\
\text { environment }\end{array}$ & $25(27.5)$ & $11(12.1)$ & $8(8.8)$ & $4(4.4)$ & $8(8.8)$ & $4(4.4)$ & $2(2.2)$ & $11(12.1)$ & $14(15.4)$ & $4(4.4)$ \\
\hline
\end{tabular}

alarms. This is almost similar to the findings by Aysha and Ahmed, ${ }^{[21]}$ who reported that none of the nurses had received training before the implementation of the clinical alarm nursing intervention program. Overall, the majority of the nurses did not receive any form of training on alarm management systems; however, a study in by Mirhafez et al. ${ }^{[2]}$ in Iran revealed that nurses needed such training. Wyckoff ${ }^{[7]}$ also agreed with the need for further training coupled with simulation training regarding better alarm usage.

\section{Alarm-related information}

Although the operator education and training on clinical alarm management was low, a greater number of nurses indicated that they understood the purpose of clinical alarms, thus agreeing with the findings of Cho et al. ${ }^{[16]}$ Nevertheless, operator alarm-related information on distracted attention indicated that the staff did not feel overwhelmed and were responsive to the alarming limits, thus making it an unnecessary area of concern in the present study. However, Baillargeon ${ }^{[23]}$ highlighted delayed responses to alarm limits occurring due to an overwhelming number of alarms sounding at the same time.

Passive patient causes in the form of clinically non-actionable alarms, also known as nuisance alarms, were highlighted in the present study. Although the ICU nurses in the present study did have an understanding of their roles and expectations with regard to alarm management, the frequency of the nuisance alarms was acknowledged as a cause for delays in their responses to these alarming limits. This concurred with the findings of Casey et al.. ${ }^{[15]}$ where most nurses agreed to the existence of non-actionable alarms, which disrupted patient care. The increased frequency of false alarms did predispose the nursing staff to alarm fatigue ${ }^{[24]}$ and consequently negative clinical consequences for patient safety and care. ${ }^{[25]}$ Bell ${ }^{[26]}$ also confirmed that due to the many potential alarms that one could be exposed to from the various medical equipment, the risk of desensitisation to the alarming limits was high and could cause a patient safety concern.

Human factors design always comes into play when looking to improve human performance with regards to the use of equipment. ${ }^{[27]}$ A significant number of nurses in the present study indicated that they understood the need for differentiating between the priority alarms based on the parameters and their impacts on multiple senses, thus agreeing with the findings of Cho et al. ${ }^{[16]}$ The role of human factors is coupled with the environmental space and the staff was well aware of the existing policies for alarm management systems available within their ICU environments. However, these policies could be reinforced to address staff that were not confident with alarm management. Bell ${ }^{[26]}$ indicated that the development of a hospital or unit policy on appropriate parameters was implemented specifically to meet patients' clinical needs.

\section{Barriers to the management of clinical alarms}

The present study highlighted difficulties in setting alarms properly and lack of training on alarm systems as the top two challenges. This contrasted with the findings of Funk et al., ${ }^{[14]}$ Casey et al.$^{[15]}$ and Mirhafez et al., ${ }^{[22]}$ who identified that frequent false alarms caused reduced attention and inadequate numbers of staff to respond to alarms as the most common barrier to the management of clinical alarms. Although $11 \%$ of the ICU 
nurses had not received training, $47.8 \%$ of the respondents stated that the lack of training on the alarm systems was their biggest issue. According to the ACCE Healthcare Technology Foundation, ${ }^{[19]}$ for a clinical alarm to be effective, it needed to be only activated by a problem that would adversely affect the patient. The nurses or other healthcare workers had to then identify the source and correct the identified problem to prevent a patient event. However, this simple concept has still not resulted in clinical alarm systems that are user-friendly and ensure patient safety.

\section{Study limitations}

Only one private hospital was used as the study setting, therefore generalisation of the study findings to other private settings and state hospitals cannot be made. The instrument used the Likert scale, which was suitable for the data being collected, but the inclusion of the neutral response and missing data had the potential to affect the quality of the data collected. Respondents were asked to recall information on how they responded to clinical alarms in ICUs, creating a possibility of recall bias. There was also the possibility of information bias, where the respondents may have given information regarded as desirable for the researchers to hear, although not necessarily a true reflection of how they understood clinical alarms in ICU settings.

\section{Recommendations}

Due to technological advancements in the healthcare sector, nursing education and training should incorporate devices and alarm management for ICU nurses of all categories. In addition, representatives of companies that sell medical equipment need to increase their frequency and involvement with education around the devices.

Replicable research is recommended in more hospitals, including public hospital ICUs, to investigate the similarities and differences, as well as to gain a better understanding of the alarm management system within the healthcare sector in SA. Policies that are existent in the facility need to be reinforced and communicated to the staff.

\section{Conclusion}

Although a greater number of intensive care nurses knew the purpose of the clinical alarms, the complexity in setting the alarms, limited training and existence of false alarms was evident. These further impacted on how nurses respond to clinical alarms in ICU, thus potentially compromising patient safety. Therefore, continuous education and in-service training to create awareness about alarm management may be beneficial.

Declaration. None.

Acknowledgements. None.

Author contributions. AR and PB conceptualised the study, analysed and interpreted the data. AR, GC and PB drafted and critically revised the manuscript. All the authors approved the final manuscript for publication. Funding. None.

Conflicts of interest. None.
1. Poncette AS, Spies C, Mosch L, et al. Clinical requirements of future patient monitoring in the intensive care unit: Qualitative study. JMIR Med Inform 2019;7(2):1-12. https://doi. org/10.2196/13064.

2. Lopes IS. Alarm fatigue: A technology hazard. Master's Theses, Dissertations, Graduate Research and Major Papers Overview 2014:246. https://doi.org/10.28971/532014LI46

3. Meng'anyi LW, Omondi LA, Muiva MN. Assessment of nurses' interventions in the management of clinical alarms in the critical care unit, Kenyatta National Hospital, a cross sectional study. BMC Nurs 2017;16(41):1-9. https://doi.org/10.1186/s12912-017-0235-1

4. Sebastian V, Brown $\mathrm{CH}$. Alarm management: A systems approach to patient safety. In: International Conference on Applied Human Factors and Ergonomics. Cham: Springer, 2017;601(1):63-72. https://doi.org/10.1007/978-3-319-60486-2_6

5. Ergezen FD, Kol E. Nurses' responses to monitor alarms in an intensive care unit: An observational study. Intensive Crit Care Nurs 2020;1(59):102845. https://doi.org/10.1016/j. iccn.2020.102845

6. Despins LA. Factors influencing when intensive care unit nurses go to the bedside to investigate patient related alarms: A descriptive qualitative study. Intensive Crit Care Nurs 2017;43:101107. https://doi.org/10.1016/j.iccn.2017.04.003

7. Wyckoff M. Improving how we use and respond to clinical alarms. Am Nurse Today 2009;4(9):37-39.

8. Bagshaw SM, Opgenorth D, Potestio M, et al. Healthcare provider perceptions of causes and consequences of ICU capacity strain in a large publicly funded integrated health region: A qualitative study. Crit Care Med 2017;45(4):e347-356. https://doi.org/10.1097/ region: A qualitative st

9. Özcan E, Birdja D, Simonse L, et al. Alarm in the ICU! Envisioning patient monitoring and alarm management in future intensive care units. In: Service Design and Service Thinking in Healthcare and Hospital Management. Cham: Springer, 2019:421-446. https://doi. org/10.1007/978-3-030-00749-2_24

10. Schatz MR. Nursing practice and decision-making process in response to monitor alarms among critical care nurses. https://repository.arizona.edu/handle/10150/620966 (accessed 2 August 2020).

11. Institue EC. Top 10 health technology hazards for 2015. Health Devices 2014;1:3-6. www.ecri org/2015hazards (accessed 20 July 2020).

12. Welch J. An evidence-based approach to reduce nuisance alarms and alarm fatigue. Biomed Instrum Technol 2011;45(s1):46-52. https://doi.org/10.2345/0899-8205-45.s1.46

13. Petersen EM, Costanzo CL. Assessment of clinical alarms influencing nurses' perceptions of alarm fatigue. Dimens Crit Care Nurs 2017;36(1):36-44. https://doi.org/10.1097/ DCC. 0000000000000220

14. Funk M, Clark JT, Bauld TJ, et al. Attitudes and practices related to clinical alarms. Am J Crit Care 2014; 23(3):e9-e18. https://doi.org/10.4037/ajcc2014315

15. Casey S, Avalos G, Dowling M. Critical care nurses' knowledge of alarm fatigue and practices towards alarms: A multicenter study. Intensive Crit Care Nurs 2018;48:36-41. https://doi. org/10.1016/j.iccn.2018.05.004

16. Cho OM, Kim H, Lee YW, et al. Clinical alarms in intensive care units: Perceived obstacles of alarm management and alarm fatigue in nurses. Health Inform Res 2016;22(1):46-53. https:// doi.org/10.4258/hir.2016.22.1.46

17. Shepherd M. Systems approach to medical device safety: In: Dyro J, ed. Clinical Engineering Handbook. AMsterdam: Elsevier, 2004:246-249.

18. South African Nursing Council. Pretoria: SANC, 2016. http://www.sanc.co.za/stats/Stat2016/ Year\%202016\%20Registrations\%20of\%20Practitioners\%20Stats.pdf (accessed 10 December 2020)

19. Clark T, David Y, Baretich M, et al. Impact of clinical alarms on patient safety. ACCE Healthcare Technology Foundation 2006:1-20. http://thehtf.org/white\%20paper.pdf.

20. George D, Mallery P. Reliability analysis. SPSS for Windows, step by step: A simple guide and reference, 14th ed. Boston: Allyn \& Bacon, 2003:222-232.

21. Aysha ZM, Ahmed SE. The effect of implementing clinical alarm nursing intervention program on nurses' knowledge, practice and patient outcomes at intensive care unit. Am J Nurs Res 2019;7(5):824-835. https://doi.org/10.12691/ajnr-7-5-16

22. Mirhafez SR, Movahedi A, Moghadam-Pasha A, et al. Perceptions and practices related to clinical alarms. I Nurs Forum 2019;54(3):369-375. https://doi.org/10.1111/nuf.12338.

23. Baillargeon E. Alarm fatigue: A risk assessment. MSc thesis. Providence: Rhode Island College, 2013. https://digitalcommons.ric.edu/etd /216/ (accessed 24 July 2020).

24. Kuckartz Pergher A, Lyra Da Silva RC. Alarm's fatigue: Integrative review. J Nurs 2013;7(4) https://doi.org/10.5205/reuol

25. Phillips Healthcare. Taking alarm management from concept to reality: A step by step guide. Netherlands. Koninklijke Philips N.V 2013;1-16. https://www.philips.nl/c-dam/b2bhc/us whitepapers/alarm-systems-management/An-action-Plan.pdf (accessed 24 July 2020).

26. Bell L. Monitor alarm fatigue. Am J Crit Care 2010;19(1):38. https://doi.org/10.4037/ ajcc 2010641

27. Shaver EF, Braun CC. The return on investment (ROI) for human factors \& ergonomics initiatives. http://www.benchmarkrs.com/_uploads/the-roi-human-factors-and-ergonomics. pdf (accessed 24 July 2020).

Accepted 12 May 2021. 